\title{
Central auditory processing outcome after stroke in children
}

\author{
Processamento auditivo central em crianças com acidente vascular cerebral \\ Karla M. I. Freiria Elias, Carolina Camargo Oliveira, Marina Junqueira Airoldi, Katia Maria D. Franco, Sônia \\ das Dores Rodrigues, Sylvia Maria Ciasca, Maria Valeriana L. Moura-Ribeiro
}

\begin{abstract}
Objective: To investigate central auditory processing in children with unilateral stroke and to verify whether the hemisphere affected by the lesion influenced auditory competence. Method: 23 children (13 male) between 7 and 16 years old were evaluated through speech-in-noise tests (auditory closure); dichotic digit test and staggered spondaic word test (selective attention); pitch pattern and duration pattern sequence tests (temporal processing) and their results were compared with control children. Auditory competence was established according to the performance in auditory analysis ability. Results: Was verified similar performance between groups in auditory closure ability and pronounced deficits in selective attention and temporal processing abilities. Most children with stroke showed an impaired auditory ability in a moderate degree. Conclusion: Children with stroke showed deficits in auditory processing and the degree of impairment was not related to the hemisphere affected by the lesion.
\end{abstract}

Keywords: auditory perception, childhood, stroke.

RESUMO

Objetivo: Investigar as habilidades de processamento auditivo central em crianças com acidente vascular cerebral (AVC) unilateral e verificar se o hemisfério cerebral afetado influiu na competência auditiva. Método: 23 crianças (13 meninos) entre 7 e 16 anos foram avaliados através dos testes de fala com ruído (fechamento auditivo); dicótico de dígitos e de dissílabos alternados (atenção seletiva); padrão temporal de frequência e duração (processamento temporal) e seus resultados comparados aos de crianças controles. A competência auditiva foi estabelecida segundo o desempenho na habilidade de análise auditiva. Resultados: Foi constatado desempenho similar entre os grupos na habilidade de fechamento auditivo e défices acentuados nas habilidades de atenção seletiva e processamento temporal. A maioria das crianças com AVC apresentou comprometimento da habilidade auditiva em grau moderado. Conclusão: Crianças com AVC apresentaram alterações do processamento auditivo e o grau do comprometimento não se relacionou com o hemisfério afetado pela lesão.

Palavras-chave: percepção auditiva, infância, acidente vascular cerebral.

Childhood stroke were long considered rare and benign. However, 10 to $25 \%$ of the affected children die; among survivors, $25 \%$ show recurrence that is closely related to the worsening in the prognosis and, $66 \%$ have neurological, cognitive, behavioral or, learning problems $s^{1,2,3,4,5,6}$. Regarding auditory function, there are few studies involving childhood stroke in complete contrast to the relevance that this function assumes for the language and for learning. In this research area, Elias and Moura-Ribeiro ${ }^{7}$ found deficits in auditory selective attention in stroke children. Another study, involving neonatal stroke, revealed difficulty of comprehension, which refers to the in-depth evaluation of the auditory function ${ }^{8}$.
In this study, we evaluate the central auditory processing (CAP) in stroke children, classify the performance and verify whether the lesion side influences auditory competence.

\section{METHOD}

The study was approved by the Committee on Ethics of the Faculty of Medical Sciences at the Universidade Estadual de Campinas in accordance with the Regional Health Counsel's resolution 196/96 (Protocol 642/2005). The parents signed the consent form. 
Twenty three children (13 male) with unilateral arterial stroke, between 7 and 16 years, were evaluated. They were right-handed before the stroke and/or presented a negative family history of left-handedness, and were followed from the acute phase of the disease onwards. This group will be referred as study group (SG).

The diagnosis was confirmed by clinical and neuroimaging investigations and, the definition of the areas affected by the vascular lesion used the magnetic resonance (at $1.5 \mathrm{~T}$ ) as reference. For its inclusion, the image had to confirm the involvement of the central auditory pathways and/or adjacent areas that consist of cortical and subcortical structures and interhemispheric connections, defined on basis of current scientific understanding 9 .

The SG was matched with a control group (CG) consisting of healthy, right-handed children with matching age, sex and socio-economic level. In the match by age, a maximum difference of 6 months was permitted.

All children had normal peripheral auditory, language, cognition and attention abilities. The speech-language evaluation was based on standardized tests using screening procedure and thematic images in spontaneous and semispontaneous conversation. The auditory evaluation used audiometric tests (pure-tone audiometry, speech audiometry, tympanometry, ipsilateral and, contralateral acoustic reflex threshold). The neuropsychological assessment included Luria-Nebraska, Wechsler Intelligence Scale for Children (WISC-III), Bender Visual Motor Gestalt test and the Test of School Performance.

The exclusion criteria were: bilateral stroke, recurrent episodes, sickle cell disease, epilepsy and, psychiatric disorders. Children with impairments related to language, auditory sensitivity, ossicular mobility in the middle ear and reflex responses to acoustic stimulation were also excluded, as well as those with an IQ below 70 .

\section{Auditory processing tests}

A CAP assessment included speech-in-noise ( $\mathrm{SiN})$, dichotic digits (DD), staggered spondaic word (SSW), pitch pattern sequence (PPS) and, duration pattern sequence (DPS). All with normative values established and validated for the Brazilian population ${ }^{10}$.

The tests were administered by the Interacoustic AC-30 audiometer in a sound-treated room and were presented at $50 \mathrm{~dB}$ sensation level, obtained by the pure-tone audiogram average.

The SiN test is composed of 25 monosyllabic words presented simultaneously with an ipsilateral white noise in a relation of $+5 \mathrm{~dB}$ and, the subjects have to repeat the words.

The DD test is composed of dissyllabic digits. A different pair of digits, 20 in total, is given simultaneously to each ear, and the subject has to repeat all four digits.
The SSW test is composed of 40 items of four dissyllabic words. The first and fourth words were presented in a non-competing condition and the second and third ones were presented in a partially overlapping way, forming the competition condition, and, the subject has to repeat all four words.

The PPS test consists of a presentation of 60 sequences composed by three tone bursts that combine a low (880 $\mathrm{Hz})$ and high frequency $(1122 \mathrm{~Hz})$, with inter tone intervals of $200 \mathrm{~ms}$. In each sequence, two of the tone bursts are of the same frequency and, one tone is of a different frequency that was presented in a binaural way. In the first 30 items the subject is required to hum the sequence, and in the last one, to name it.

The DPS test consists of a presentation of 60 sequences composed by three tone bursts of $1000 \mathrm{~Hz}$, that vary in duration, short (250 ms) and long (500 ms), with an inter tone interval of $300 \mathrm{~ms}$. In the first 30 items, the subject is required to hum the sequence and, in the last one, to name it. This test was not applied to children under 12 years due to standardization.

\section{Auditory competence}

The auditory competence was scored into four categories according to the percentage of correct responses in the competition conditions of SSW ${ }^{10}$ : performances of $90 \%$ or better was considered normal; 80 to $90 \%$ were considered mild; 60 to $80 \%$ moderate and; 0 to $59 \%$ severe auditory processing disabilities.

We sought to verify whether the side of the lesion affected the degree of auditory competence which was analyzed under two different distributions: (1) children with normal auditory competence were compared with those presenting disorders in any degree, and (2) healthy and mild disorders children were compared with those who showed moderate and severe disorders.

Statistical analysis included, in the comparison of continuous measurement, Wilcoxon test for related samples. In order to verify association or to compare proportions we used Fisher's exact test; significance level of $5 \%$.

\section{RESULTS}

The SG data considering the age of onset, the age at auditory evaluation and lesion characteristics were included in Table 1. We found prevalence of stroke in male children, involvement of the middle cerebral artery, right hemisphere, ischemic type and cortico-subcortical extension. In the acute episode, the average age of SG was 5 years and 8 months. At the time of the assessment, the SG had a mean age of 12 years and 7 months and CG, 12 years and 6 months. 
Table 1. Stroke in Children - identification data and cerebral impairment.

\begin{tabular}{|c|c|c|c|c|c|c|c|}
\hline Subject & Sex & $\begin{array}{l}\text { At stroke } \\
\text { age }\end{array}$ & $\begin{array}{c}\text { At testing } \\
\text { age }\end{array}$ & Artery & Type & Extension & Imaging Findings \\
\hline \multicolumn{8}{|c|}{ Right Lesion } \\
\hline S1 & M & 3y $8 m$ & 11 y $3 \mathrm{~m}$ & MCA & $\mathrm{I}-\mathrm{H}$ & $\mathrm{C}-\mathrm{Sc}$ & PrCG SFG MFG CSO I CR IC CN LN \\
\hline S2 & M & $7 y$ & $11 \mathrm{y} 6 \mathrm{~m}$ & MCA & 1 & C-Sc & PrCG IFG STG I LN CN IC \\
\hline S3 & M & 3y & $12 y 9 m$ & MCA & I & Sc & T LN CN IC \\
\hline S4 & M & $4 y 11 \mathrm{~m}$ & $15 y 8 m$ & MCA & । & C & SP \\
\hline S5 & $\mathrm{F}$ & $10 y 6 m$ & $15 y$ & MCA & । & Sc & IC \\
\hline S6 & $\mathrm{F}$ & $2 y 4 m$ & $10 y 11 \mathrm{~m}$ & MCA & । & $\mathrm{Sc}$ & $T$ \\
\hline S7 & $F$ & $4 m$ & $15 y 2 m$ & MCA & I & $\mathrm{Sc}$ & LN IC \\
\hline S8 & F & $6 y 6 m$ & $16 y$ & MCA & $\mathrm{I}-\mathrm{H}$ & C-Sc & $\mathrm{TP}$ \\
\hline s9 & M & $13 y 1 m$ & $16 y 7 m$ & MCA/ACA & । & C-Sc & $\mathrm{TP}$ \\
\hline S10 & M & $8 y$ & $14 \mathrm{y} 6 \mathrm{~m}$ & MCA & I & C & $\mathrm{TP}$ \\
\hline S11 & $\mathrm{F}$ & $7 y$ & $16 y 10 m$ & MCA & । & C-Sc & PCG P CC \\
\hline $\mathrm{S} 12$ & M & $6 y 6 m$ & $9 y 7 m$ & MCA & I & Sc & EC IC \\
\hline S13 & $M$ & $7 y$ & $8 y$ & MCA & $\mathrm{I}-\mathrm{H}$ & $\mathrm{C}-\mathrm{Sc}$ & $\mathrm{PO}$ \\
\hline S14 & M & $1 \mathrm{~m} \mathrm{20d}$ & $8 y 8 m$ & MCA & $\mathrm{H}$ & $\mathrm{C}-\mathrm{Sc}$ & P CC LN CN EC IC \\
\hline \multicolumn{8}{|c|}{ Left Lesion } \\
\hline S15 & M & $5 y 4 m$ & $7 m$ & MCA & I & C-Sc & FTP LN CN IC PR \\
\hline S16 & M & $4 y 10 m$ & 11 y $2 \mathrm{~m}$ & MCA/ACA & $\mathrm{I}-\mathrm{H}$ & $\mathrm{C}-\mathrm{Sc}$ & LOG IFG Po P MTG I STG PhG LN CN EC IC \\
\hline S17 & $\mathrm{F}$ & $1 \mathrm{y} 1 \mathrm{~m}$ & $10 y 5 m$ & MCA & । & Sc & Pt \\
\hline S18 & $\mathrm{F}$ & $7 y 1 m$ & $7 y 11 \mathrm{~m}$ & MCA & । & C-Sc & SFG MFG PrCG LN CN EC IC \\
\hline S19 & M & $1 y 2 m$ & $16 y$ & MCA & । & C-Sc & IFG MFG PrCG PCG P \\
\hline S20 & M & 11 y $8 m$ & $12 y 8 m$ & MCA & $\mathrm{H}$ & C & $\mathrm{FT} \mathrm{I}$ \\
\hline S21 & $\mathrm{F}$ & $10 y$ & $14 \mathrm{y} 6 \mathrm{~m}$ & MCA & । & Sc & LN CN IC EC \\
\hline S22 & $\mathrm{F}$ & $7 y 5 m$ & $13 y 2 m$ & ACA & $\mathrm{I}-\mathrm{H}$ & C-Sc & SoMG CG CN IC T CC \\
\hline$S 23$ & $\mathrm{~F}$ & $3 y$ & $8 y 6 m$ & MCA & । & C-Sc & $\mathrm{FP}$ \\
\hline
\end{tabular}

M: male; F: female; y: years; m: months; d: days; MCA: middle cerebral artery, ACA: anterior cerebral artery; R: right; L: left; I: ischemic; I-H: secondary hemorrhagic conversion of ischemia; H: hemorrhagic; Age SG/Stroke: age at time of stroke. C: cortical; Sc: subcortical. CG: cingulate gyrus; CN: caudate nucleus; CR: corona radiata; CSO: centrum semiovale; EC: external capsule; FTP: fronto-temporoparietal; FP: frontoparietal; I: insula; IC: internal capsule; InC: inferior colliculus; IFG: inferior frontal gyrus; LN:lenticular nucleus; LOG: lateral orbital gyrus; MFG: middle frontal gyrus; MTG: middle temporal gyrus; P: parietal; Pt: putamen; PCG: postcentral gyrus; PrCG: precentral gyrus; PhG: parahippocampal gyrus; PO: parietooccipital; Po: pars opercularis; PR: perisylvian region; SC: superior colliculus; SFG: superior frontal gyrus; SoMG: superior orbitary medial gyrus; SP: superior parietal; STG: superior temporal gyrus; T: thalamus; TP: temporoparietal.

The results at CAP assessment were in Table 2. CG showed responses within the normal range in all tests.

In SiN, SG and CG showed, respectively, an average score of $90.3 \%$ and $93.6 \%$ with the right ear and, $90.6 \%$ and $93.7 \%$ with the left. In both analyses, there was no significant difference (Wilcoxon test: $\mathrm{p}=0.0660$ for the right ear and $\mathrm{p}=0.1056$ for the left ear), Figure 1. Through descriptive analysis we found that a single SG child (S14) showed insufficient right answers; the others reached levels within the normal range, similar to the CG, Table 2.

In DD, the average of identifications for SG and CG were, respectively, $94 \%$ and $99.5 \%$ for the right ear, and $93.3 \%$ and $98 \%$ for the left. In both, statistically significant (Wilcoxon test: $\left.\mathrm{p}=0.0002^{*}\right)$, Figure 2 . We found that 12 SG children performed below the normal range, and the lesion involved the right hemisphere in 7 children and the left in 5. Regarding only children with right-sided lesions, the auditory deficits involved both ears in three children, exclusively the ear contralateral to the lesion in three children, and the ipsilateral in one child. The children with left hemisphere lesions, deficits were bilateral in two children, in the contralateral ear in two children, and in the ipsilateral in one child.
In SSW, in the competitive conditions, the average of identifications for SG and CG was $80 \%$ and $97.5 \%$ in the right condition, and $79.4 \%$ and $96 \%$ in the left condition. In both, the difference was statistically significant (Wilcoxon test: $\mathrm{p}<0.0001 \%$ ), Figure 3. In the non-competitive conditions, the average score for SG and CG was $93.3 \%$ and $99.6 \%$ for non-competitive right ear, and $96.1 \%$ and $99.8 \%$ for the non-competitive left ear. In both, there was a significant difference (Wilcoxon test: $\mathrm{p}<0.0001^{*}$ ), Figure 4.

In the competitive condition, 17 SG children performed below normal patterns: the lesion involved the right hemisphere in 10 children and the left one in 7 . In right-sided stroke, deficits were observed in both ears in 5 children, in the contralateral ear in 4 and, in the ipsilateral in one child. In the left-sided stroke, auditory deficits were bilateral in 4 children, in the ear contralateral to the lesion in two and, the ipsilateral in one child.

In the non-competitive condition, 7 SG children performed below normal patterns: the lesion involved the left hemisphere in 5 children and the right in two. Among leftsided lesions, deficits were observed only in the right ear, contralateral to the lesion. In right-sided lesions, the deficit 
Table 2. Stroke in children - central auditory test results and the degree of auditory processing competence.

\begin{tabular}{|c|c|c|c|c|c|c|c|c|c|c|c|}
\hline \multirow[b]{2}{*}{ Subject } & \multicolumn{2}{|c|}{$\mathrm{SiN}$} & \multicolumn{2}{|c|}{ DD } & \multicolumn{2}{|c|}{ SSW } & \multicolumn{2}{|c|}{ PPS } & \multicolumn{2}{|c|}{ DPS } & \multirow{2}{*}{$\begin{array}{c}\text { AuditoryCompetence } \\
\text { level }\end{array}$} \\
\hline & $\mathrm{R} \%$ & L\% & $\mathrm{R} \%$ & L\% & $\mathrm{CR} \%$ & CL\% & $\mathrm{H} \%$ & N\% & $\mathrm{H} \%$ & $\mathrm{~N} \%$ & \\
\hline 1 & 88 & 92 & 96 & 96 & 95 & 20 & 73 & 83 & na & na & severe \\
\hline 2 & 92 & 92 & 96 & 92 & 95 & 75 & 100 & 90 & na & na & moderate \\
\hline 3 & 88 & 92 & 96 & 96 & 93 & 90 & 90 & 57 & 0 & 0 & competent \\
\hline 4 & 96 & 84 & 100 & 100 & 98 & 80 & 97 & 90 & 93 & 93 & mild \\
\hline 5 & 84 & 80 & 92 & 92 & 95 & 93 & 100 & 90 & 97 & 93 & competent \\
\hline 6 & 92 & 92 & 88 & 92 & 68 & 88 & 97 & 77 & na & na & moderate \\
\hline 7 & 88 & 88 & 84 & 92 & 90 & 73 & 60 & 37 & 60 & 67 & moderate \\
\hline 8 & 92 & 92 & 92 & 92 & 78 & 90 & 63 & 70 & 53 & 63 & moderate \\
\hline 9 & 96 & 100 & 88 & 92 & 100 & 100 & 83 & 97 & 97 & 97 & competent \\
\hline 10 & 96 & 96 & 96 & 96 & 87 & 85 & 100 & 97 & 97 & 97 & mild \\
\hline 11 & 100 & 100 & 100 & 100 & 100 & 90 & 100 & 97 & 90 & 90 & competent \\
\hline 12 & 88 & 84 & 92 & 96 & 70 & 83 & 97 & 97 & na & na & moderate \\
\hline 13 & 96 & 76 & 92 & 92 & 63 & 35 & 87 & 60 & na & na & severe \\
\hline 14 & 64 & 76 & 92 & 96 & 55 & 63 & 27 & 43 & na & na & severe \\
\hline 15 & 92 & 96 & 96 & 92 & 85 & 88 & 77 & 77 & 0 & 0 & mild \\
\hline 16 & 96 & 92 & 92 & 96 & 20 & 93 & 97 & 100 & na & na & severe \\
\hline 17 & 88 & 92 & 96 & 92 & 98 & 98 & 97 & 100 & na & na & competent \\
\hline 18 & 96 & 100 & 96 & 92 & 83 & 63 & 80 & 84 & na & na & moderate \\
\hline 19 & 96 & 96 & 96 & 92 & 55 & 85 & 67 & 57 & 73 & 47 & severe \\
\hline 20 & 92 & 96 & 96 & 96 & 98 & 95 & 97 & 80 & 83 & 97 & competent \\
\hline 21 & 88 & 92 & 88 & 84 & 78 & 85 & 0 & 0 & 50 & 53 & moderate \\
\hline 22 & 92 & 92 & 92 & 96 & 68 & 95 & 93 & 33 & 0 & 0 & moderate \\
\hline 23 & 76 & 84 & 96 & 92 & 68 & 60 & 33 & 60 & na & na & moderate \\
\hline
\end{tabular}

L: left ear; R: right ear; H: humming; N: Naming; na: not assessed.

SiN: speech-in-noise; DD: dichotic digits; SSW: staggered spondaic word; PPS: pitch pattern sequence; DPS: duration pattern sequence.

involved the contralateral ear in one child and the ipsilateral in another.

In PPS, in humming stage, the average score of SG and CG was, respectively, $78.9 \%$ and $98.3 \%$ (Wilcoxon test: $\mathrm{p}=0.0002 *$ ). In naming stage, the average score of the groups was $72.9 \%$ and $94.5 \%$ (Wilcoxon test: $\mathrm{p}=0.0001$ ), Figure 5 .

In DPS, in humming stage, the average score of SG and CG was, respectively, $61.0 \%$ and $98.8 \%$ (Wilcoxon test:

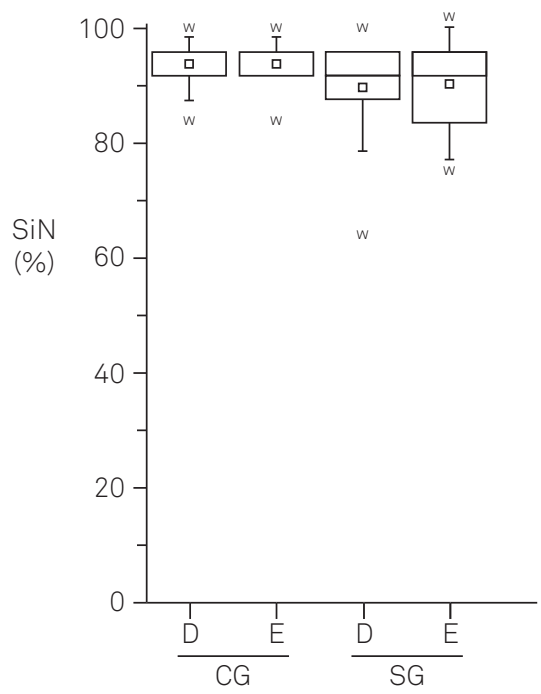

Figure 1. Speech in Noise test (SiN) - Study group (SG) and control group (CG) performances. $\left.\mathrm{p}=0.0017^{*}\right)$. In naming stage, the average of the groups was $61.3 \%$ and $95.5 \%$ (Wilcoxon test: $\mathrm{p}=0.0020^{*}$ ), Figure 6 .

\section{Auditory competence}

The SG analysis revealed normal performance in 6 children, mild impairment in 3, moderate in 9 and, severe in five children. The comparison of competence in both the first (Fischer's test: $\mathrm{p}=0.6600$ ), as the second distribution

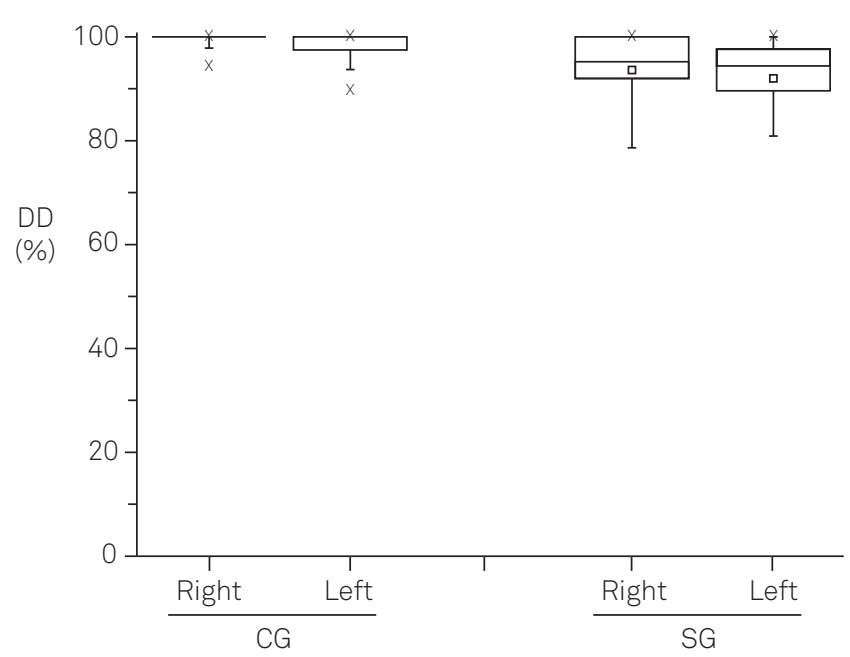

Figure 2. Dichotic Digits test (DD) - Study group(SG) and control group (CG) performances. 


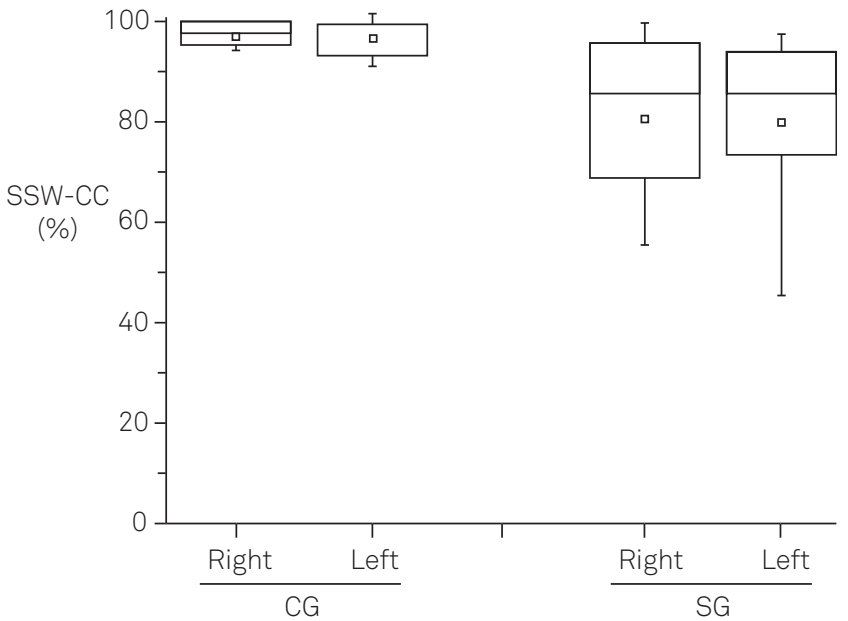

Figure 3. Staggered Spondaic Wod test/Competitive condition (SSW/CC) - Study group (SG) and control group (CG) performances.

(Fischer's test: $\mathrm{p}=0.6693$ ) showed no significant difference regarding the affected hemisphere.

\section{DISCUSSION}

We evaluated the auditory function in children with unilateral arterial stroke through the application of CAP tests. SG age at acute phase of disease varied among the children evaluated as well as the type, extension and time elapsed between injury and assessment. Of all the factors traditionally related to the long-term outcome, the age at stroke is considered one of the main predictors of prognosis. The recovery in very young children is better than the older one and adults at least for the most essential aspects of motor and language functions ${ }^{11}$. However, recent studies have suggest that the plasticity and reorganization after early

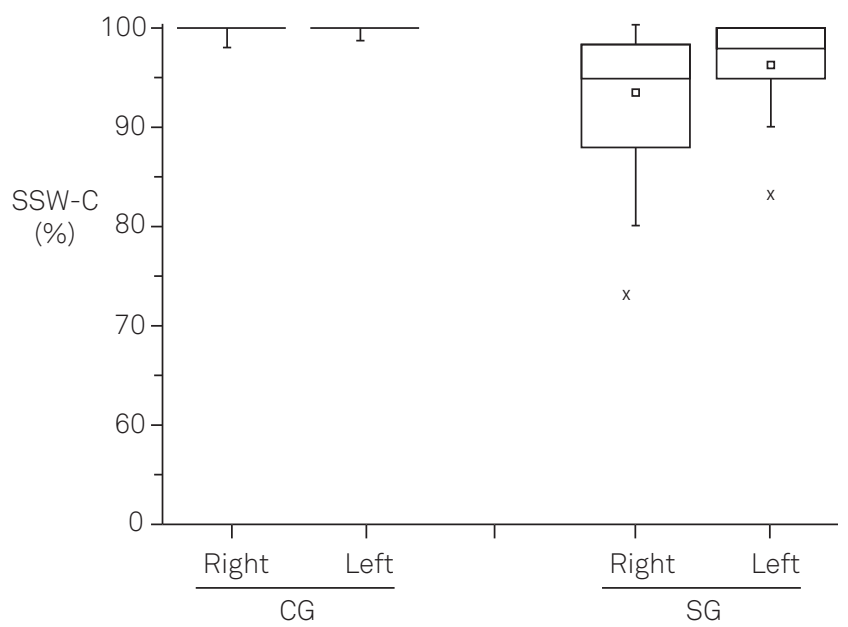

Figure 4. Staggered spondaic word test/Non competition condition (SSW/C) - Study group (SG) and control group (CG) performances.

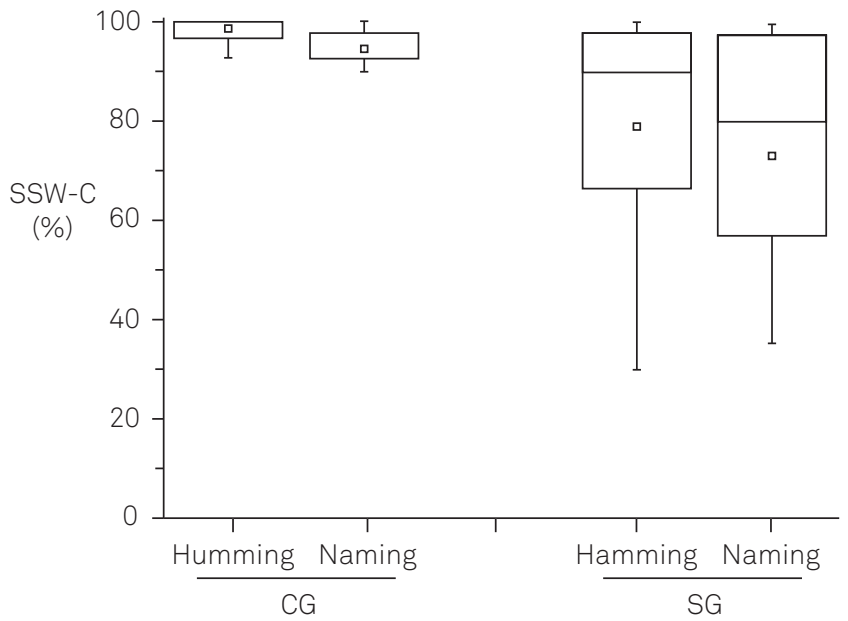

Figure 5. Pitch pattern sequence test (PPS) - Study group (SG) and control group (CG) performances.

injury are not always associated with positive and adaptive long-term outcomes especially for higher-level and laterdeveloping abilities ${ }^{3,11,12}$. The final result would be a consequence of brain development pattern (throughout the childhood / later-maturing areas dependent upon proper development of early-maturing one), the modulating effect of variables on injury and which aspect of a particular function - motor, cognitive, linguistic, behavior - will be in focus ${ }^{11}$. Cnossen et al. ${ }^{3}$ compared stroke children between 1 months and 2 years at onset with children older than 2 years and found that younger age and laterality of injury were related to worse neurological outcome ${ }^{3}$. Already in reviewing Amlie-Lefond et al. ${ }^{12}$ was not observed laterality effect in neuropsychological outcome, and there is no clear relation between the location and cognitive prognosis, but the earlier age at stroke was confirmed as a factor for poor outcome. Westmacott et al. ${ }^{11}$ verified that children affected before the age of 28 days performed more poorly than

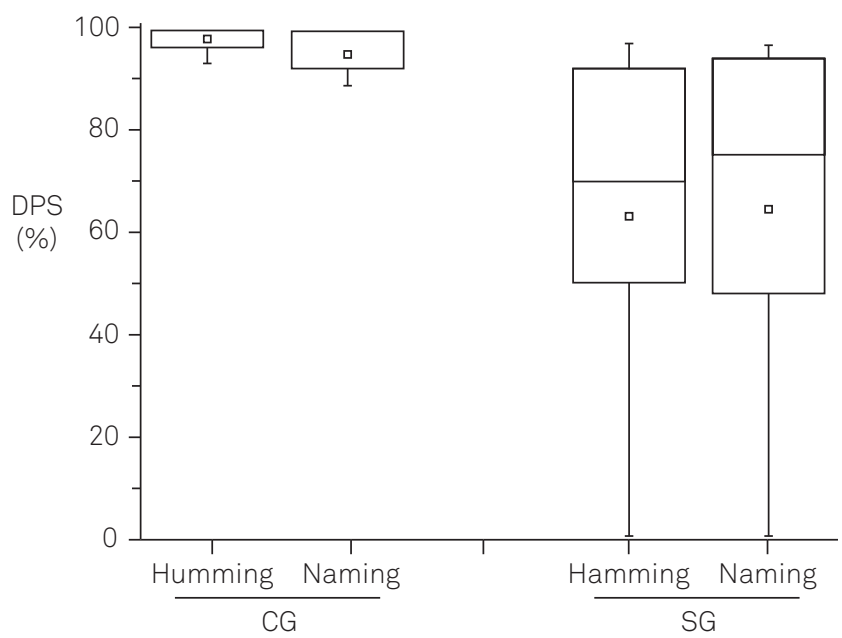

Figure 6. Duration pattern sequence test (DPS) - Study group (SG) and control group (SG) performances. 
children with similar subcortical stroke occurred between 1 months and 5 years of age or between 6 and 12 years on intellectual measures; but in cortical one, the period of greatest vulnerability were between 1 and 5 years of age. In the same study was verified that cortical-subcortical lesions was more detrimental to cognitive outcome than cortical or subcortical one and, this extension effect occurred independent of size of lesion, age at onset and laterality. Lately it has been suggested that the time until the evaluation can contribute to the worse outcomes observed in younger children $^{3,11}$. However, a study that investigated this factor did not confirm this relationship ${ }^{11}$.

In our study, the behavioral tests employed were directed to different aspects of auditory processing such as auditory closure, selective attention and temporal processing abilities.

In SiN, the studied groups had similar performance. The auditory closure ability, required in the detection task of speech-in-noise signals is dependent on several factors, including peripheral auditory sensitivity, sound localization and lateralization and, binaural release from masking, largely measured by low brainstem structures ${ }^{14}$, which were spared in the children of this study. However, in some SG children, the lesions involve areas that participate in phonological processing, also required by the task, and this condition may have hampered, although it has not prevented the recognition of the words heard; Figure 1. The majority of the SG showed the rate of correct answers within the normal range, but the values were lower than those achieved by $\mathrm{CG}$, a finding also verified in other studies ${ }^{11,15}$.

In DD, we verified a significant difference between groups in both ears. In this test, as it is a dichotic presentation and it uses verbal stimuli, it would be expected a greater number of errors with the ear contralateral to the lesion or deficits in both ears when the lesion involved only the left hemisphere, as observed in adults ${ }^{14,16,17}$. In our study, this pattern was predominant, but we also observed ipsilateral deficits both in right and left hemisphere lesions, similar in Isaacs et al. ${ }^{18}$ and a previous study by Elias and Moura-Ribeiro ${ }^{7}$. In both studies, the diversity of the results was related to the variables of the lesion, while Isaacs et ${ }^{18}$ consider in particular, the presence of epilepsy.

In SSW, we verified also a significant difference between groups in both ears, and in the two conditions of the test. This test is one of the most complex in clinical routine, since it is heavily linguistically loaded ${ }^{14,19}$, enabling more extensive neural network in each hemisphere. It reflects the effects of asymmetry in the processing of this type of stimulus (for the benefit of the left hemisphere) and of the interhemispheric transfer rate ${ }^{20}$. Thus, because it is a task of great linguistic and cognitive demand, it would recruit neural networks of both hemispheres, responsible for sensory and high-order processing ${ }^{20}$. The greater demand would justify the performance difference between both dichotic tests, DD and SSW, in the competitive condition and, between competitive and non-competitive conditions of SSW. As it can be seen in Table 2, many children who showed unilateral deficits in DD, which was linguistically less marked, increased the number of errors or changed the configuration of the loss, changing from unilateral in DD to bilateral lowering in SSW, regardless of the laterality of lesion. It was also found that there were a greater number of errors in the competitive conditions, considered the most difficult, both in right and left hemisphere lesions. The issue of the task's demand was also observed in cognitive studies of stroke children, in which language deficits appeared only when more complex tasks were involved ${ }^{4}$. Coinciding with study that reported more cognitive problems, attributing them to the failures in the proper development of new post-stroke neural pathways, which were identified only in individuals long-term monitored for more than six years after the stroke, at the time they had to face more challenging activities ${ }^{3}$.

The PPS and DPS tests, require the right hemisphere integrity in the humming stage and, when the linguistic labelling is involved, both hemispheres and corpus callosum is necessary $^{11,20}$. In the PPS we observed poor performance in both stage or solely in the naming and, in the DPS of both stages, regardless the hemisphere affected. A study using only the naming stage, involving adults with lesions similar to some SG children also observed impairment in both tests ${ }^{16}$.

Regarding the auditory competence, we verified that SG ability, unlike CG which showed typical performance, varied in broad spectrum, with efficiency ranging from normal to severe, with the majority of them showing moderate level impairment. These dysfunctions may explain the difficulties in establishing efficient communication when in adverse hearing environments, since no child of the study showed significant changes in language, attention or memory as demonstrated by the neuropsychological evaluation they went through ${ }^{10,14,19}$.

In addition, we sought to verify whether the side of the lesion interfered with the auditory analysis ability. In order to do so, we verified the auditory competence in two different classifications. This alternative aimed to eliminate the possibility of underestimating or overestimating our results, as proposed by deVeber et al. ${ }^{1}$, because when analyzing patients with adequate performance together with those with mild changes, we reduced the chance of detecting an auditory abnormality in which, in practice, the functional consequence would be very mild, with interference in very specific or minimal hearing situations. However, regardless of the classification used, we found no significant effects of this aspect in the auditory processes, although this influence has been quite documented ${ }^{15,21,22,23}$.

Besides the small number of children involved, our limitations include the wide range of stroke characteristics, the differences in the time elapsed until audiological 
evaluation and also, the lack of a stroke control group with lesions that do not affect the auditory pathways. Because it is an uncommon condition in childhood, multicenter studies would be need for a large samples composition. However, this is one of the few studies that have proposed to evaluate CAP in post-stroke children, a paucity also observed in the adult population ${ }^{17}$, a phase of life in which such occurrences are considerably more prevalent. Regarding our children, they were all monitored since the acute phase of the disease, had their attention, memory and other cognitive abilities considered as satisfactorily evolved, and we could assume that the communication and learning difficulties reported by the children themselves, their parents and teachers result from the changes in auditory abilities now identified and graduated. Our results indicate that children with stroke have auditory functional limitations that may impact the performance of various activities of daily life, with social and educational outspreading. These findings will involve the modifying of the monitoring of these patients; the inclusion of the CAP assessment in routine care in services that help stroke children, and due to these changes, the selection of special strategies for rehabilitation and education, that finally allows the recovery or the remediation of communication and learning difficulties.

In conclusion the study of childhood stroke revealed auditory closure ability similar to that of control children and significant deficits in selective attention and temporal processing abilities. Most children showed moderate impairment of auditory abilities and, the degree of competence did not correlate with the hemisphere affected by the stroke.

\section{References}

1. deVeber GA, MacGregor D, Curtis R, Mayank S. Neurologic outcome in survivors of childhood arterial ischemic stroke and sinovenous thrombosis. J Child Neurol 2000;15:316-324.

2. Gordon AL, Ganesan V, Towell A, Kirkham FJ. Functional outcome following stroke in children. J Child Neurol 2002;17:429-434.

3. Cnossen M, Aarsen F, Akker SLJ, et al. Paediatric arterial ischaemic stroke: functional outcome and risk factors. Dev Med Child Neurol 2010;52:394-399.

4. Kolk A, Ennok M, Laugesaar R, Kaldoja ML, Talvik T. Long-term cognitive outcomes after pediatric stroke. Pediatr Neurol 2011;44:101-109.

5. Tsze DS, Valente JH. Pediatric stroke: a review. Emerg Med Int 2011:1-10.

6. Rodrigues SD, Ciasca SM, Guimarães IE, et al. Does stroke impair learning in children? Stroke Res Treatment 2011:1-6.

7. Elias KM, Moura-Ribeiro MV. Stroke caused auditory attention deficits in children. Arq Neuropsiquiatr 2013;71:11-17.

8. Airoldi MJ. Aspectos evolutivos de crianças com acidente vascular cerebral isquêmico perinatal [Dissertação de mestrado]. Campinas: Universidade Estadual de Campinas; 2012.

9. American Speech-Language-Hearing Association.Central auditory processing: current status of research and implications for clinical practice. Task force on central auditory processing consensus development. Am J Audiol 1996;5:41-52.

10. Pereira LD, Schochat E. Testes auditivos comportamentais para avaliação do processamento auditivo central. São Paulo: Pró-Fono; 2011.

11. Bellis TJ. Assessment and management of central auditory processing disorders in the educational setting - form science to practice. 2nd ed. Clinton Park, New York: Delmar Learning; 2003.
12. Massi G, Marcheschi M, Brovedani P, Pfanner P. Neuropsiologia delle encephalopatie focali non evolutive dell'infanzia. Minerva Pediatr 1993;45:235-246.

13. Bamiou DE, Musiek FE, Stow I, et al. Auditory temporal processing déficits in patients with insular stroke. Neurology 2006;67:614-619.

14. Bamiou DE, Werring D, Cox K, Stevens, et al. Patient-reported auditory functions after stroke of the central auditory pathway. Stroke 2012;43:1285-1289.

15. Isaacs E, Christie D, Vargha-Khadem F, Mishkin M. Effects of hemispheric side of injury, age at injury, and presence of seizure disorder on functional ear and hand asymmetries in hemiplegic children. Neuropsychologia 1996;34:127-137.

16. Alvarez AMMA, Balen AS, Misorelli MIL, Sanchez ML. Processamento auditivo central: proposta de avaliação e diagnóstico diferencial. In: Munhoz MSL, Caovilla HH, Silva MLG, Ganança MM, editors. Audiologia clínica. São Paulo: Atheneu; 2000. p. 103-120.

17. Bamiou DE, Sisodiya S, Musiek FE, Luxon LM. The role of the interhemispheric pathway in hearing. Brain Res Rev 2007;56:170-182.

18. Hogan AM, Kirkham FJ, Isaacs EB. Intelligence after stroke in childhood: review of the literature and suggestions for future research. J Child Neurol 2000;15:325-332.

19. Brizzolara D, Pecini C, Brovedani P, Ferretti G, Cipriani P, Cioni G. Timing and type of congenital brain lesion determine different patterns of language lateralization in hemiplegic children. Neuropsychologia 2002;40:620-632.

20. Guimarães IE, Ciasca SM, Moura-Ribeiro MV. Cerebrovascular disease in childhood: neuropsychological invstigation in 14 cases. Arq Neuropsiquiatr 2007;65:41-47. 